\title{
Indicators of anemia and physical growth in schoolchildren from the Ouest and Sud-Est Departments of Haiti: a cross-sectional study
}

Thomas A. Weppelmann ${ }^{1 *}$, Michael E. von Fricken², Roseline Masse ${ }^{3}$, Gedeon Gelin ${ }^{4,5}$, J. Glenn Morris Jr. ${ }^{6,7}$, Bernard A. Okech ${ }^{6,8}$ and Valery Madsen Beau De Rochars ${ }^{6,9}$

\begin{abstract}
Background: The identification and correction of malnutrition in children remains a critical public health issue in many developing countries. In this study, the rate of anemia and standardized indicators of physical growth were investigated in schoolchildren from Haiti.

Methods: Hemoglobin concentrations, height, and weight were collected from schoolchildren $(n=615)$ and evaluated by World Health Organization (WHO) standardized classifications for anemia and child growth. Data on glucose-6-dehydrogenase (G6PD) deficiency and current or previous malaria infection available for all students; a subset of anemia and non-anemic males $(n=43)$ were tested for serum ferritin. School A $(n=504)$ had a school-based supplemental nutrition program, while School B $(n=111)$ did not.

Results: Anemia was identified in $48.3 \%$ of students (95\% Cl: $44.3,52.3)$, and not associated with BMI Z scores $(P=0.28)$ or serum ferritin concentrations $(P=0.17)$. The average $Z$ scores for body mass index (BMI) of students at School A was within the normal range, while $Z$ scores for BMl at School B were below average. Compared to school A, students at School B had significantly higher $(P<0.001)$ rates of anemia $(44.4 \%$ vs $65.8 \%)$ and were significantly $(P<0.001)$ more likely to be underweight (16.5\% vs $43.2 \%)$.

Conclusions: The high prevalence of anemia in children with and without normal BMls represents a major public health concern that warrants further investigation with more comprehensive methods. This study may also highlight some potential benefits of in-school nutritional supplementation programs in achieving lower rates of anemia and reaching WHO standards for child growth.
\end{abstract}

Keywords: Anemia, Child growth, Haiti, School-aged children

\section{Background}

In developing countries, malnutrition remains among the most important underlying factors for the global burden of disease, directly attributed to over 300,000 deaths per year and indirectly responsible for more than half of all deaths in children [1]. Poor cognitive development, delays in physical growth, decreased organ and

\footnotetext{
* Correspondence: twepp002@fiu.edu

${ }^{1}$ Herbert Wertheim College of Medicine, AHC-2 (3rd floor M1 Mailbox),

Florida International University, 11200 Southwest 8th Street, Miami, FL 33199,

USA

Full list of author information is available at the end of the article
}

immune system function, and increased morbidity and mortality, have all been associated with malnutrition $[2,3]$. Anemia is often linked with malnutrition in these settings, reflecting a series of complex interactions between inadequate dietary intake of key nutrients, exposure to infectious diseases, and underlying genetic factors [4]. Considering that as of 2014, Haiti was ranked 101 out of 107 countries around the world and last in Latin America and the Caribbean in food security, malnutrition in Haitian children represents a major public health concern [5]. 
Currently, sparse information is available about the nutritional status of school-aged children in Haiti, who are often at risk of being overlooked when prioritizing national nutrition interventions [6]. In the 2012 National Haitian Health Survey, anemia was identified as a major health concern, where $65 \%$ of children under five had some form of anemia [7]. A recent review of anemia in Latin America and the Caribbean reported that Haiti had the highest prevalence of anemia at $45.5 \%$; however anthropomorphic measurements of child development or underlying pathophysiological mechanisms were not investigated [8]. Moreover, Haiti is the only remaining country in the Caribbean with endemic malaria transmission [9]. Since malaria infections or treatment with antimalarial drugs can induce anemia [10], especially in individuals with glucose-6-phosphate dehydrogenase (G6PD) deficiency [11], investigation of the relationships between malaria, G6PD deficiency, and anemia in this population could provide useful information for future malaria elimination efforts in Haiti [12]. For these reasons, a cross-sectional study was conducted to evaluate these relationships among schoolchildren in Haiti.

\section{Methods}

\section{Ethical approval}

Sample collection and enrollment were approved by the University of Florida based Institutional Review Board, the Haitian-based Institutional Review Committee, and the Office of Research Protections, United States Army Medical Research and Materials Command. Participants and their parents/guardian were given opportunities to ask our enrolling physicians and health professionals questions during informational sessions prior to informed consent. As the study population was mostly children, consent was provided by a parent or legal guardian prior to their participation.

\section{Study population}

Schoolchildren $(n=615)$ were enrolled from two schools located in the Ouest and Sud-Est departments of Haiti between February 2013 and May 2013. In the Ouest department, participants $(n=504)$ were recruited from the Christianville Foundation school (School A) in Gressier. In the Sud-Est department, participants $(n=111)$ were recruited from the Hossana Baptist School (School B) located in Jacmel. Though a convenience sample was used to investigate indicators of child growth and the prevalence of anemia, certain selection criteria were used to control for potential confounding and gain adequate power for hypothesis testing. In an attempt to include children of similar socioeconomic status, both schools selected were private, operated by non-governmental organizations (NGOs), and charged a similar tuition for attendance. To examine the potential effects of diet on anemia and malnutrition, one school with a supplementary nutrition program and one without such a program were selected. Children attending School A were given one meal every day at school in the form of farmed tilapia, chicken eggs, pasta, green leafy vegetables, or beans, while School B had no organized in-school nutrition program.

\section{Sample collection and laboratory analysis}

After informed consent and enrollment, participant age (months), gender, height $(\mathrm{cm})$, weight $(\mathrm{kg})$, and hemoglobin concentration $(\mathrm{g} / \mathrm{dl})$ were collected using a tape-measure, portable scale and a digital hemoglobin meter (HemoCue ${ }^{\circ}$ $\mathrm{Hb} 201$ plus, Hemocue Incorporated, Cypress, Ca, USA), following standard methods [13]. Blood samples were collected by venipuncture and screened for G6PD deficiency (G6PD kit \#345B, Trinity Biotech, St. Louis, MO, USA), current malaria infection using a rapid diagnostic test (First Response Malaria Combo, Premier Medical Corporation Ltd., Kachigam, India), and previous malaria infection (presence of antibodies toward Plasmodium falciparum MSP-1 or AMA-1 antigens using indirect ELISA) as previously described $[14,15]$. A subset of 43 male students from the 90th and 10th percentiles of hemoglobin concentrations were selected at random and screened for serum ferritin concentrations using an IMMULITE 2000 Immunoassay System (Siemans Healthcare GmbH, Erlangen, Germany). Only male students were selected to examine the association between serum ferritin and anemia to remove the possibility of iron deficiency anemia caused by menstruation in females.

\section{Classification of anemia and child development}

The WHO classifications for mild, moderate, and severe anemia determined by measurement of hemoglobin concentration at sea level $(\mathrm{g} / \mathrm{L})$ were used. Thresholds for mild, moderate, and severe anemia are defined for population members stratified into four groups: children aged five to eleven years, children aged twelve to fourteen years, males above the age of fifteen, and females above the age of fifteen [16]. Child growth indicators were used as a proxy for malnutrition by comparison to the World Health Organization (WHO) international reference population, which contains anthropometric measurements from children and adolescents from around the world [17]. Measurements of height and weight were used to calculate a body mass index (BMI) that was normalized by gender and age to generate $Z$ scores to determine whether the participant's physical development was different from the mean growth indicators for a child of the same age and gender [18]. Deficiencies in child growth were defined by $\mathrm{Z}$ scores two standard deviations below mean heightfor-age (stunting), weight-for-age (wasting), and weightfor-height (underweight); with the additional inclusion of 
thinness (thin) defined by a Z score one standard deviation below the mean BMI.

Simple logistic regression models were used to determine if gender, age, enrollment location, presence of G6PD deficiency, serum ferritin concentration, and current or previous malaria infection were associated with any form of anemia (mild, moderate, or severe anemia) or moderate to severe anemia. The associations between gender, age, enrollment location, hemoglobin concentration or anemia and the presence of growth deficiencies (stunting, wasting, under/overweight) were also examined using simple logistic regression models. Comparisons of anemia and indicators of child growth between schools were adjusted for gender, age, and other relevant factors using multivariate logistic regression models to account for potential differences between schools. All statistical analyses were conducted with Stata software (Stata v12, StataCorp ${ }^{\circledR}$, College Station Texas, TX, USA), with $P$ values less than 0.05 considered statistically significant.

\section{Results}

The prevalence of any, mild, moderate, and severe anemia are summarized by gender, enrollment location, and WHO defined groups in Table 1; with the distributions of hemoglobin concentrations by WHO anemia group in Fig. 1. The prevalence of any form of anemia was $48.3 \%$ (95\% CI: $44.3,52.3 \%$ ), with the highest rates observed in children aged 5 to $11(51.8 \%)$ and girls over the age of $15(68.8 \%)$. Overall, there was no difference between the rates of male and female anemia $(47.6 \%$ vs $48.8 \%$ ); however, being anemic or having moderate to severe anemia was significantly different $(P<0.001)$ by

Table 1 Prevalence of mild, moderate, severe anemia by gender, location, and WHO population group

\begin{tabular}{llllll}
\hline WHO anemia classification & \multicolumn{5}{l}{$l$} \\
\hline Participants & Obs. & \multicolumn{4}{l}{ Prevalence by anemia category (\%) } \\
\hline Gender & (n) & Any & Mild & Moderate & Severe \\
Males & 250 & 47.6 & 22.8 & 24.0 & 0.8 \\
Females & 365 & 48.8 & 24.4 & 23.0 & 1.4 \\
Location & & & & & \\
$\quad$ School A & 504 & 44.4 & 24.4 & 19.2 & 0.8 \\
$\quad$ School B & 111 & 65.8 & 20.7 & 42.3 & 2.7 \\
Age & & & & & \\
$\quad 5$ to 11 & 301 & 51.8 & 18.9 & 31.6 & 1.3 \\
$\quad$ 12 to 14 & 156 & 43.6 & 26.3 & 16.7 & 0.6 \\
$\quad$ Male $\geq 15$ & 65 & 27.7 & 23.1 & 4.6 & 0.0 \\
Female $\geq 15$ & 93 & 68.8 & 35.5 & 31.2 & 2.2 \\
$\quad$ Total & 615 & 48.3 & 23.7 & 23.4 & 1.1 \\
\hline
\end{tabular}

enrollment location. Compared to students at School A, those attending School B were 2.4 times more likely to have some form of anemia (95\% CI OR: 1.56, 3.69) and 3.27 times more likely to have moderate or severe anemia (95\% CI OR: 2.12, 5.04). The association between enrollment location and anemia remained significant after adjustment for age, gender, G6PD activity and BMI Z scores using multivariate models $(\mathrm{OR}$ anemia $=2.68, P<0.001$; OR moderate or severe $=3.34, P<0.001)$. Almost $10 \%$ of this population $(60 / 547)$ had moderate to severe G6PD deficiency (activity less than 10\% of the population average), where G6PD deficiency was not associated with mild, moderate, or severe anemia $(P=0.28)$. As presented in Fig. 2, no significant correlation was identified between hemoglobin concentration and G6PD activity $(P=0.15)$. All serum ferritin concentrations in the subset tested were within the normal range (7-142 $\mathrm{ng} / \mathrm{mL})$ for children under 15 years of age [18] and were not associated with participant hemoglobin concentration $(P=0.17)$. Using serological measures and rapid testing, $15.7 \%$ of this population had been previously infected with malaria $(88 / 560)$ and $0.16 \%(1 / 615)$ had a current malaria infection, neither of which was associated mild, moderate, or severe anemia ( $P>0.5$ in all cases).

Summary statistics from the sample population for BMI, and indicators of child growth are presented by gender, school, and age in Table 2. Overall, the rates of stunting $(5.5 \%)$ and wasting $(1.2 \%)$ were relatively low, with severe forms in less than $1 \%$ of participants. The highest rates of growth deficiency were observed in children aged 5 to 11 years, with $10.4 \%$ having at least two standard deviations below the normal height-for-age, and over half (58.3\%) below one standard deviation below the normal BMI. The percentage of underweight children decreased with age to $16.5 \%$ in males and $8.5 \%$ in females aged 15 years and older. Males consistently had higher rates of deficient growth indicators than females, with significantly higher $(P=0.002)$ likelihood of being underweight compared to females $(\mathrm{OR}=1.86$; 95\% CI OR: 1.26. 2.75). By enrollment location, School B had consistently lower BMIs, with students over three times more likely to be thin $(\mathrm{OR}=3.86)$ or underweight $(\mathrm{OR}=3.59)$ compared to students attending School A $(P<0.001$, both cases). The association between enrollment location and deficient growth indicators remained significant after adjustment for age, gender, and anemia using multivariate models (OR thin $=3.7, P<0.001$; OR underweight $=3.5, P=0.005)$. A comparison of the distributions of BMI Z scores from both schools is presented in Fig. 3. As shown, the distribution of $Z$ scores from students attending School A are within the normal range and included zero in the 95\% confidence interval (95\% CI $\mathrm{Z}_{\mathrm{BMI}}$ : $\left.-0.13,0.08\right)$; whereas the distribution of $\mathrm{Z}$ scores from School B were significantly below the normal range 


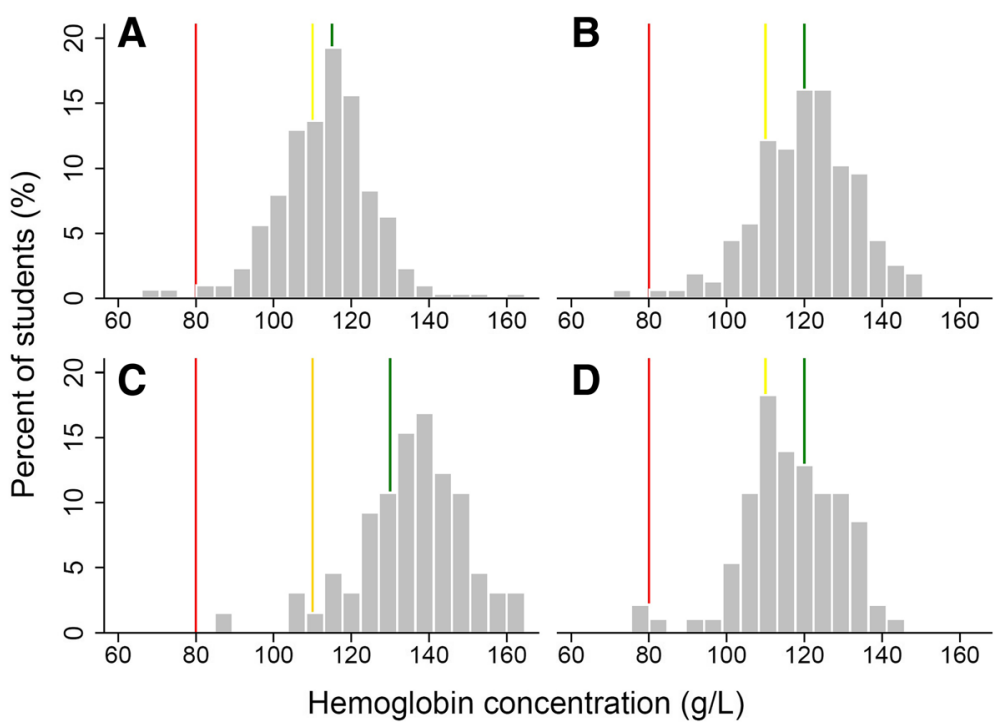

Fig. 1 Prevalence of anemia by gender and age group. The prevalence of mild, moderate, and severe anemia in the study population is shown with respect to the World Health Organization $(\mathrm{WHO})$ classifications of anemia using hemoglobin concentration at sea level ( $\mathrm{g} / \mathrm{L})$. These include children aged five to eleven years old (panel $\mathbf{a}$ ), children aged twelve to fourteen years old (panel $\mathbf{b}$ ), males above the age of fifteen (panels $\mathbf{c}$ ) and females above the age of fifteen (panels $\mathbf{d}$ ). The threshold for non-anemia (green line), moderate anemia (yellow line), and severe anemia (red line) are shown based on the WHO classifications for each group of the four groups

(95\% CI Z $\left.\mathrm{BMI}_{\mathrm{BM}}-0.90,-0.46\right)$. Anemia was not associated with being underweight, other dichotomous indicators of child growth deficiencies $(P>0.3$, in all cases), or with continuous BMI $\mathrm{Z}$ score stratified by participant age $(P=>0.2$ in all cases, Fig. 4).

\section{Discussion}

According to the $\mathrm{WHO}$, a prevalence of anemia greater than $40 \%$ in this population represents a severe public health concern [17]. Though the prevalence of children that were stunted $(5.5 \%)$, wasted $(1.2 \%)$, underweight
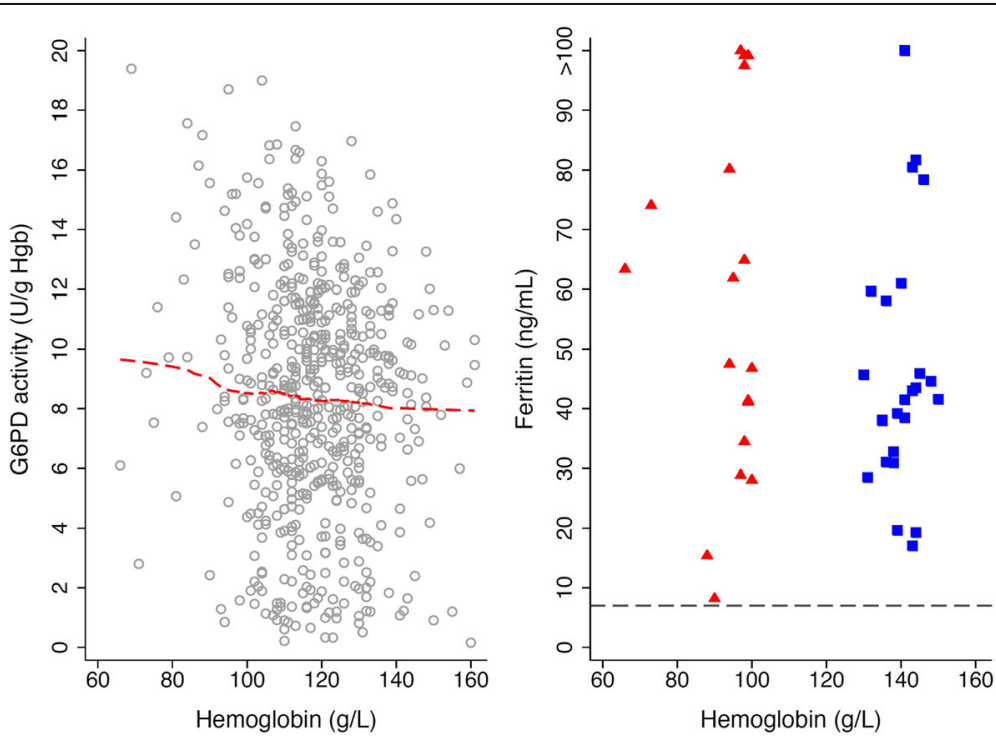

Fig. 2 Relationships between G6PD activity, ferritin, and hemoglobin. The relationship between glucose-6-phosaphte dehydrogenase (G6PD) activity and hemoglobin concentration ( $\mathrm{g} / \mathrm{L}$ ) is presented (left panel) by for all participants (gray circles) along with the locally weighted scatterplot smoothing line (LOESS, red dashed). The concentration of serum ferritin $(\mathrm{ng} / \mathrm{mL})$ from a subset of participants with hemoglobin concentrations less than or equal to $100 \mathrm{~g} / \mathrm{L}$ (anemic, red triangle) and hemoglobin concentrations above $130 \mathrm{~g} / \mathrm{L}$ (non-anemic, blue squares) are presented (right panel) with the threshold for normal serum ferritin concentration for children aged 6 months to 15 years of age ( $7 \mathrm{ng} / \mathrm{mL}$, dotted gray line) 
Table 2 Anthropometric indicators of child growth by gender, location, and age group

\begin{tabular}{|c|c|c|c|c|c|c|c|c|c|c|c|}
\hline \multirow{2}{*}{$\begin{array}{l}\text { Participants } \\
\text { Gender }\end{array}$} & \multicolumn{6}{|c|}{ Body Mass Index (BMI) } & \multicolumn{2}{|l|}{ Stunting } & \multicolumn{3}{|c|}{ Wasting } \\
\hline & (n) & $>2 \mathrm{SD}$ & $>1 \mathrm{SD}$ & $<-1 \mathrm{SD}$ & $<-2$ SD & $<-3 \mathrm{SD}$ & $<-2 \mathrm{SD}$ & $<-3$ SD & (n) & $<-2 \mathrm{SD}$ & $<-3 \mathrm{SD}$ \\
\hline Males & 250 & 3.6 & 12.0 & 26.4 & 5.2 & 2.0 & 6.0 & 0.8 & 109 & 1.8 & 1.8 \\
\hline Females & 365 & 4.7 & 15.9 & 16.4 & 3.3 & 0.5 & 5.2 & 0.5 & 143 & 0.7 & 0.0 \\
\hline \multicolumn{12}{|l|}{ Location } \\
\hline School A & 504 & 4.6 & 15.9 & 16.5 & 3.0 & 1.0 & 6.2 & 0.6 & 185 & 1.1 & 0.5 \\
\hline School B & 111 & 2.7 & 7.2 & 43.2 & 9.9 & 1.8 & 2.7 & 0.9 & 67 & 1.5 & 1.5 \\
\hline \multicolumn{12}{|l|}{ Age Group } \\
\hline 5 to 11 & 301 & 11.3 & 31.3 & 58.3 & 13.0 & 4.3 & 10.4 & 2.6 & 113 & 1.2 & 0.8 \\
\hline 12 to 14 & 156 & 7.1 & 18.6 & 25.0 & 5.0 & 0.7 & 5.0 & 0.0 & - & - & - \\
\hline Male $\geq 15$ & 65 & 0.0 & 5.5 & 16.5 & 2.8 & 0.9 & 5.5 & 0.0 & - & - & - \\
\hline Female $\geq 15$ & 93 & 2.3 & 15.4 & 8.5 & 0.8 & 0.0 & 6.9 & 0.8 & - & - & - \\
\hline Total & 615 & 4.2 & 14.3 & 21.3 & 4.2 & 1.1 & 5.5 & 0.7 & 252 & 1.2 & 0.8 \\
\hline
\end{tabular}

The anthropometric measures of body mass index (BMI), height-for-age (stunting), and weight-for-age (wasting) stratified by gender, location, and age group presented by the percentage that fall under or above various standard deviations (SD) when compared to the World Health Organization global reference population

(4.2\%), or had severe anemia (1.1\%) was relatively low; more than half of children aged between 5 to 11 years had some form of anemia (51.8\%) or a weight-for-age of at least one standard deviation below the mean of the international reference population (58.3\%). The findings from this study complement the high prevalence of anemia documented in children under 5 years-of-age $[19,20]$ and suggest a trend of anemia beyond the age of 5 years. Upon further stratification by participant age (Fig. 5), other trends are also apparent; $31.6 \%$ of children between the ages of 5 and 11 have moderate anemia, which decreased to $16.7 \%$ between the ages of 12 and 14 , concurrently with an increase in a mild anemia (18.9 to $26.3 \%$ ). After the age of 15 , less than $5 \%$ of males are anemic, however females (presumably associated, at least in part, with menstruation) had increased rates of mild (35.5\%) and moderate anemia (31.2\%). The trend of increased anemia in females of gestational age was observed in both schools and warrants further investigation, considering the multitude of adverse effects maternal anemia can have on fetal development [21]. This observation could also be used to design and evaluate future

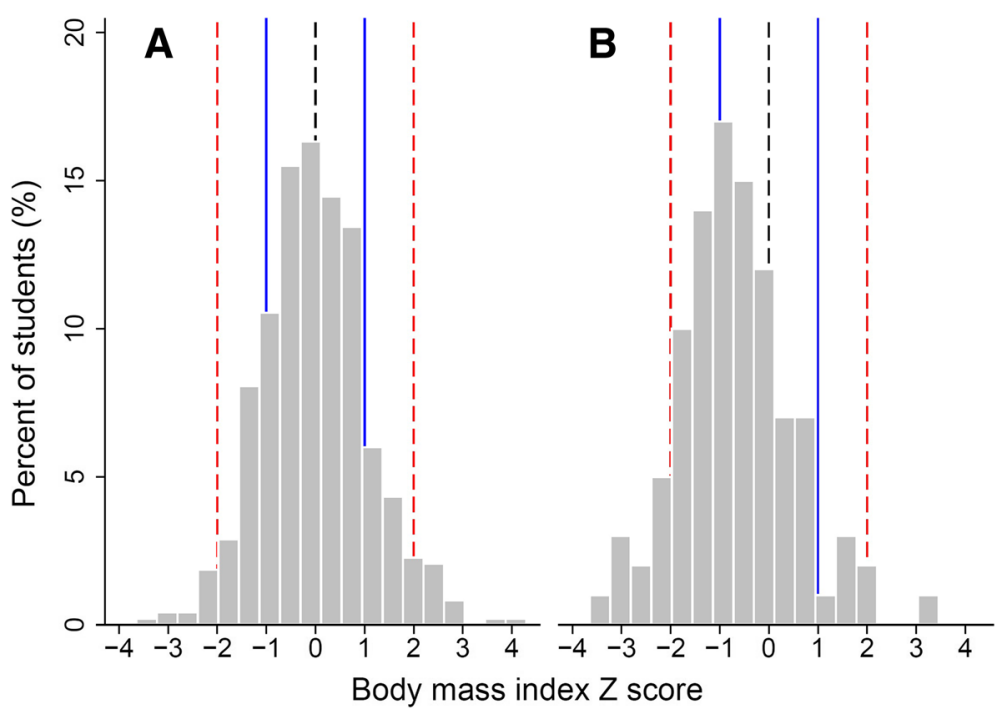

Fig. 3 Body mass index (BMI) Z-scores for schools A and B. The distributions of body mass index (BMI) Z-scores in comparison to the World Health Organization (WHO) global reference population are presented for school A (panel $\mathbf{a}$ ) and school B (panel $\mathbf{b}$ ) along with the reference lines denoting the following BMI Z-scores: mean (0, dotted black line), 1 standard deviation from mean $(-1 /+1$, solid blue line), and 2 standard deviations from the mean $(-2 /+2$ dotted red line) 


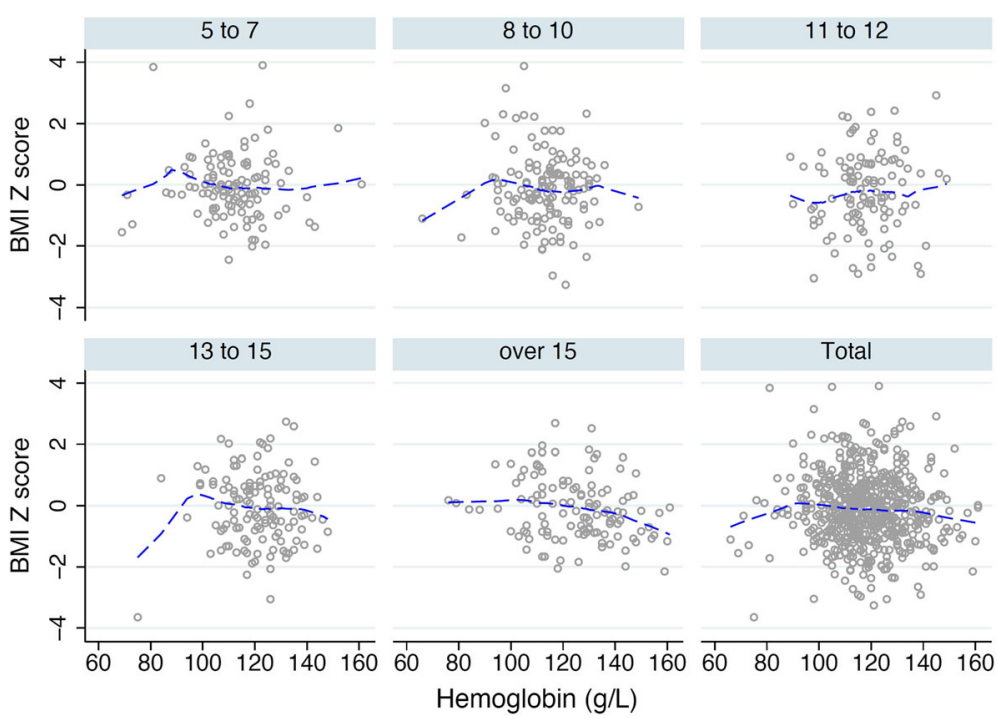

Fig. 4 Relationships between weight-for-age and hemoglobin by age group. The relationship between body mass index (BMI) Z score and hemoglobin concentration $(\mathrm{g} / \mathrm{L}$ ) is presented by age group and for all participants (gray circle), along with the locally weighted scatterplot smoothing line (LOESS, blue dashed)

interventions with iron or nutritional supplementation in females after the age of 15 .

While often regarded as a proxy for malnutrition, the causes of chronic anemia can be multifactorial, including nutritional iron deficiency, blood loss from menstruation in females, chronic inflammation, infectious diseases such as malaria or intestinal helminths, and a range of inherited hemoglobinopathies [22, 23]. In this study normal serum ferritin concentrations were identified in the subset of children tested, although future, more comprehensive studies should include other diagnostic measures of anemia such as serum iron, transferrin, total iron binding capacity, and vitamins such as B12 and folic acid [24]. Prior studies with students from School A have
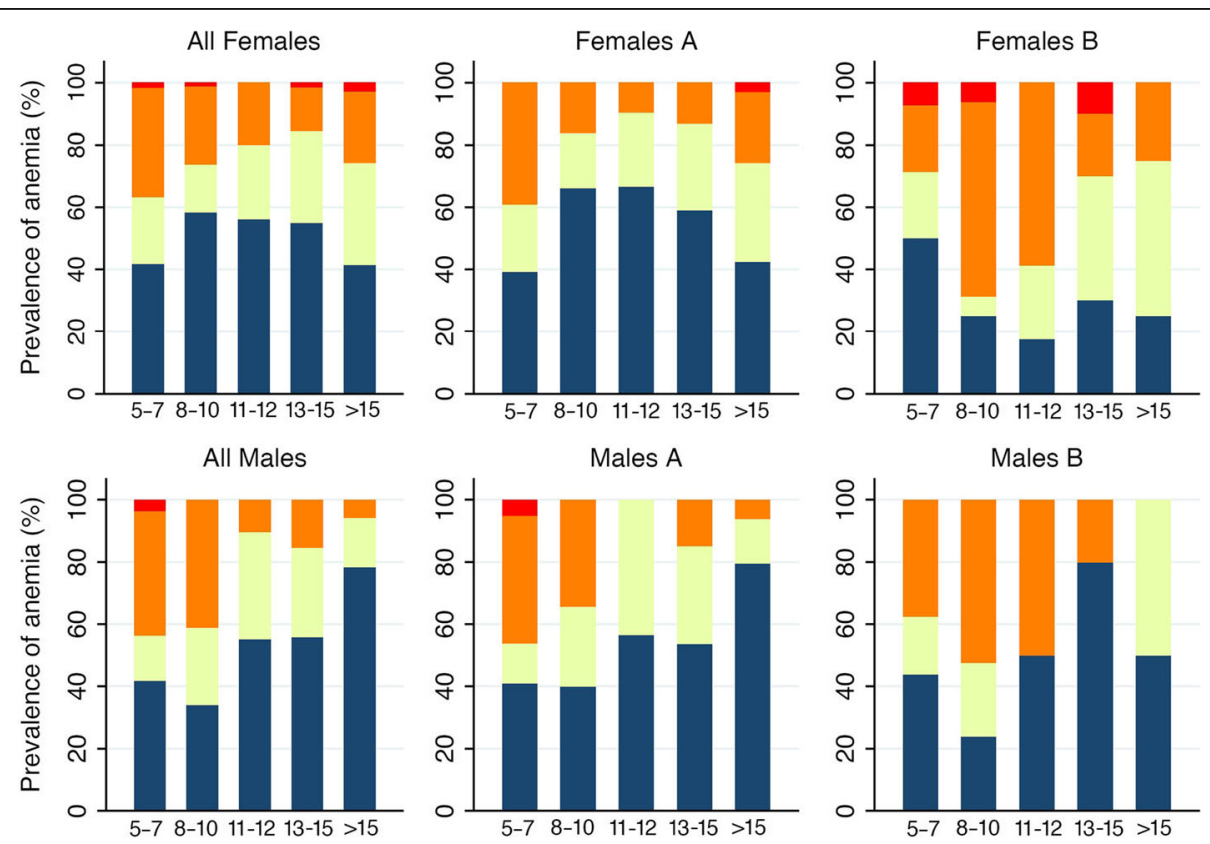

Fig. 5 Prevalence of anemia with age stratified by gender and school. The prevalence of participants that were not anemic (navy) and those with mild (light yellow), moderate (orange), or severe (red) anemia as defined by the WHO guidelines are presented with respect to age group for females (top panels) and males (bottom panels) for schools A and B separately and for all participants 
demonstrated low levels of carriage of soil-transmitted helminths [25] and national mass drug administration programs to eliminate lymphatic filariasis are active in both enrollment locations using chemotherapeutic agents also effective against the primary intestinal helminths [26]. In this study, we also found no correlation between anemia and G6PD deficiency, current, or previous malaria infections for which this study was initially designed. In the process we observed that in School A, where a supplemental nutrition program supplied daily meals with proteins and leafy vegetables, children had significantly lower rates of anemia higher growth indicators compared to School B, where no such program existed. Despite the apparent reduction of anemia and children with normalized BMIs less than the global average, high levels of mild and moderate anemia were present in both schools, suggesting that other unknown factors are also operational and represent a priority for future research.

\section{Limitations}

Although this study examined indicators of growth and anemia in Haitian schoolchildren, multiple pathways of anemia mentioned earlier were not able to be explored. The use of a convenience sample that consisted of only two enrollment sites, both schools, might not be representative of children not attending school or children from other departments of Haiti. Besides malaria, diagnostic testing for the presence of soil-transmitted helminth infections could have allowed for more adequate examination of the associations between such infections and anemia. A previous study [27] found that the prevalence of sickle cell traits in Gressier and Jacmel was between 6 and 14\%, however sickle cell anemia or thalassemia were not examined in this study. Finally, though School A had an in-school nutritional supplementation program, food journals were not used to record the dietary intake of individual students, which could have revealed heterogeneity in diets within schools and additional dietary intakes outside of school, and affected the ability to compare anemia and growth indicators between schools.

\section{Conclusions}

Given the high prevalence of anemia in children above five years of age, future demographic and health surveys should be expanded to include this potentially vulnerable subpopulation. Future investigations of the etiology of anemia in Haiti should be expanded to include more comprehensive laboratory analyses of erythrocytes, iron metabolism, biomarkers of chronic inflammation, and more adequate assessment of nutritional attainment. Such studies would be useful for creating targeted public health interventions to reduce the prevalence of anemia in Haitian schoolchildren and ensure the attainment of development goals for maternal and child health.

\section{Abbreviations}

AMA-1: Apical membrane protein one; BMI: Body mass index; ELISA: Enzymelinked immunosorbent assay; G6PD: Glucose-6-phosphate dehydrogenase; MSP-1: Merozoite surface protein one; NGO: Non government organization; RDT: Rapid diagnostic test; WHO: World Health Organization

\section{Acknowledgements}

The authors would like to extend a special thanks to the dedicated staff at the Christianville Foundation and the Hossana Baptist School, as well as the children and legal guardians of the participants. Without their support, this study would not have been possible.

\section{Funding}

This study was funded by the Armed Forces Health Surveillance Center, Global Emerging Infections Surveillance and Response Division to Bernard A. Okech and by University of Florida, College of Public Health and Health Profession funds to Michael E von Fricken.

\section{Availability of data and materials}

The dataset supporting the conclusions of this article is available in the form of an excel spreadsheet (.xls) or STATA data file (.dta) upon request from the corresponding author, Thomas A. Weppelmann.

\section{Authors' contributions}

TAW, MEV, MVB, GG, JGM, and BAO contributed to the conception and design of the study. MEV, RM, and BAO contributed to the collection of data. TAW and MEV analyzed and interpreted the results. All authors contributed to the drafting and revising of this manuscript. All authors read and approved the final manuscript.

\section{Competing interests}

The authors declare that they no competing interests.

\section{Consent for publication}

Not applicable.

\section{Ethics approval and consent to participate}

Sample collection and enrollment were approved by the University of Florida based Institutional Review Board, the Haitian-based Institutional Review Committee, and the Office of Research Protections, United States Army Medical Research and Materials Command. Participants were given opportunities to ask our enrolling physicians/health professionals questions during informational sessions prior to informed consent. The parents/guardians of study participants provided consent on their children's behalf.

\section{Author details}

${ }^{1}$ Herbert Wertheim College of Medicine, AHC-2 (3rd floor M1 Mailbox), Florida International University, 11200 Southwest 8th Street, Miami, FL 33199. USA. ${ }^{2}$ Department of Global and Community Health, George Mason University, Fairfax, VA, USA. ${ }^{3}$ Christianville Foundation, Christianville Boulevard Mareshall, Gressier, Haiti. ${ }^{4}$ Centre Haïtien de Recherche en Sciences de la Santé, Port-au-Prince, Haiti. ${ }^{5}$ College of Health Sciences and Tropical Medicine, Sainte Louis Du Noir, Haiti. ${ }^{6}$ Emerging Pathogens Institute, University of Florida, Gainesville, FL, USA. 'Department of Medicine, College of Medicine, University of Florida, Gainesville, FL, USA. ${ }^{8}$ Department of Environmental and Global Health, College of Public Health and Health Professions, University of Florida, Gainesville, FL, USA. ${ }^{9}$ Department of Health Services Research Management and Policy, University of Florida, College of Public Health and Health Professions, Gainesville, FL, USA.

Received: 22 May 2016 Accepted: 6 November 2016 Published online: 18 November 2016

\section{References}

1. Müller $\mathrm{O}$, Krawinkel M. Malnutrition and health in developing countries. Can Med Assoc J. 2005:173:279-86.

2. Black RE, Allen LH, Bhutta ZA, Caulfield LE, deOnis M, Ezzati M, et al. Maternal and child undernutrition: global and regional exposures and health consequences. Lancet. 2008;371:243-60.

3. United Nations Children's Fund, World Health Organization, The World Bank. UNICEF-WHO-World Bank Joint Child Malnutrition Estimates. (UNICEF, New York; 
WHO, Geneva; The World Bank, Washington, DC; 2012). Available at http://www. who.int/nutgrowthdb/estimates/en/.

4. Ramakrishnan U, Imhoff-Kunsch B. Anemia and iron deficiency in developing countries. In: Lammi-Keefe CJ, Couch SC, Philipson EH, editors. Handbook of nutrition and pregnancy. Totowa: Humana Press; 2008. p. 337-54.

5. Global Food Security Index (2014) Haiti Country Profile. Accessed 09 Jan 2014. Available at http://foodsecurityindex.eiu.com/Country/Details\#Haiti

6. Best C, Neufingerl N, van Geel L, van den Briel T, Osendarp S. The nutritional status of school-aged children: why should we care? Food Nutr Bull. 2010:31:400-17.

7. Ministry of Public Health and Population [le Ministère de la Santé Publique and de la Population] (MSPP), Haitian Childhood Institute [I'Institut Haïtien de I'Enfance] (IHE) and ICF International. 2013. 2012 Haïti Mortality, Morbidity, and Service Utilization Survey: Key Findings. Calverton, Maryland, USA: MSPP, IHE, and ICF International. Available at http://dhsprogram.com/ pubs/pdf/SR199/SR199.eng.pdf.

8. Mujica-Coopman MF, Brito A, Lopez de Romana D, Rios-Castillo I, Coris H, Olivares M. Prevalence of anemia in Latin America and the Caribbean. Food Nutr Bull. 2015;36(2 Suppl):S119-28. Epub 2015/07/01.

9. WHO. World malaria report. Geneva: World Health Organization; 2015.

10. Haldar K, Mohandas N. Malaria, erythrocytic infection, and anemia. Hematology/the Education Program of the American Society of Hematology American Society of Hematology Education Program. 2009:87-93. Epub 2009/12/17.

11. Mason PJ. New insights into G6PD deficiency. Br J Haematol. 1996;94:585-91.

12. Boncy PJ, Adrien P, Lemoine JF, Existe A, Henry PJ, Raccurt C, et al. Malaria elimination in Haiti by the year 2020: an achievable goal? Malar J. 2015;14(1):1-11.

13. Cogill, Bruce. 2003. Anthropometric Indicators Measurement Guide. Washington, DC: Food and Nutrition Technical Assistance (FANTA) Project, FHI 360. Available at http://www.fantaproject.org/tools/anthropometry-guide.

14. von Fricken ME, Weppelmann TA, Eaton WT, Alam MT, Carter TE, Schick L, Masse R, Romain JR, Okech BA. Prevalence of glucose-6-phosphate dehydrogenase (G6PD) deficiency in the Ouest and Sud-Est Departments of Haiti. Acta Trop. 2014;135:62-6.

15. von Fricken ME, Weppelmann TA, Lam B, Eaton WT, Schick L, Masse R, et al. Age-specific malaria seroprevalence rates: a cross-sectional analysis of malaria transmission in the Ouest and Sud-Est departments of Haiti. Malar J. 2014;13:361

16. WHO. Haemoglobin concentrations for the diagnosis of anaemia and assessment of severity, Vitamin and mineral nutrition information system. Geneva: World Health Organization; 2011. WHO/NMH/NHD/MNM/11.1 Available at http://www.who.int/vmnis/indicators/haemoglobin.pdf.

17. WHO Multicentre Growth Reference Study Group. WHO child growth standards: length/height-for-age, weight-for-age, weight-for-length, weight-for-height and body mass index-for-age: methods and development. Geneva: World Health Organization; 2006. Available at http://www.who.int/childgrowth/standards/technical_report/en/.

18. Onis M, Onyango AW, Borghi E, Siyam A, Nishida C, Siekmann J. Development of a WHO growth reference for school-aged children and adolescents. Bull World Health Organ. 2007;85:660-7.

19. Heidkamp RA, Ngnie-teta I, Ayoya MA, Stoltzfus RJ, Mamadoultaibou A, Durandisse EB, et al. Predictors of anemia among Haitian children age 6 to 59 months and women of childbearing age and their implications for programming. Food Nutr Bull. 2013;34:462-79.

20. Ayoya MA, Ngnie-Teta I, Seraphin MN, Mamadoultaibou A, Boldon E, Saint-Fleur JE, et al. 2013. Prevalence and risk factors of anemia among children 6-59 months old in Haiti. Anemia. Volume 2013, Article ID 502968 pp.1-3.

21. Handbook of Nutrition and Pregnancy, eds. Lammi-Keffe CJ, Couch SC, \& Philipson EH. Totowa: Humana Press; 2008.

22. Johnson-Wimbley TD, Graham DY. Diagnosis and management of iron deficiency anemia in the 21st century. Ther Adv Gastroenterol. 2011;4(3):177-84.

23. Stevens GA, Finucane MM, De-Regil LM, Paciorek CJ, Flaxman SR, Branca F, et al. Global, regional, and national trends in haemoglobin concentration and prevalence of total and severe anaemia in children and pregnant and non-pregnant women for 1995-2011: a systematic analysis of populationrepresentative data. Lancet Global Health.1 11):e16-e25.

24. WHO, UNICEF, UNU. Iron deficiency anaemia: assessment, prevention and control, a guide for programme managers. Geneva: World Health Organization; 2001. Available at http://www.who.int/nutrition/publications/ micronutrients/anaemia_iron_deficiency/WHO_NHD_01.3/en/index.html.

25. Beau De Rochars VEM, Alam MT, Telisma T, Masse R, Chavannes S, Anilis MG, Guillaume JH, Gelin G, Kirkpatrick EL, Desormeaux A-M, Okech BA, Weppelmann TA, Rashid M, Karst S, Johnson JA, Ali A, Morris JG Jr. 2015. Spectrum of outpatient illness in a school-based cohort in Haiti, with a focus on diarrheal pathogens. Am. J. Trop. Med. Hygiene 2015 Apr 1;92(4):752-7. doi:10.4269/ajtmh.14-0059. Epub 2015 Mar 2. PMID:25732684

26. Beau de Rochars M, Direny AD, Roberts JM, Addiss DG, Radday J, Beach MJ, Streit TG, Dardith D, Lafontant J, Lammie PJ. Community-wide reduction in prevalence and intensity of intestinal helminths as a collateral benefit of lymphatic filariasis elimination programs. Am J Trop Med Hyg. 2004;71(4):466-70.

27. Carter TE, von Fricken M, Romain JR, Memnon G, St Victor Y, Schick L, et al. Detection of sickle cell hemoglobin in Haiti by genotyping and hemoglobin solubility tests. Am J Trop Med Hyg. 2014;91(2):406-11. Epub 2014/06/25.

\section{Submit your next manuscript to BioMed Central and we will help you at every step:}

- We accept pre-submission inquiries

- Our selector tool helps you to find the most relevant journal

- We provide round the clock customer support

- Convenient online submission

- Thorough peer review

- Inclusion in PubMed and all major indexing services

- Maximum visibility for your research

Submit your manuscript at www.biomedcentral.com/submit
() BioMed Central 